\title{
Interação entre volume de vaso e competição com plantas daninhas sobre o crescimento da soja
}

\author{
Mirielle Oliveira Almeidal, Christiano da Conceição de Matos ${ }^{2 *}$, Daniel Valadão Silva \\ Renan Rodrigues Braga 4 , Evander Alves Ferreira ${ }^{5}$ José Barbosa dos Santos 6 \\ http://dx.doi.org/10.1590/0034-737X201562060003
}

\section{RESUMO}

A avaliação dos efeitos da competição das plantas daninhas sobre o crescimento da soja é efetuada por meio de ensaios em ambientes protegidos. Esses ensaios, geralmente, são feitos em recipientes (vasos) em que se testam os efeitos desejados em diferentes épocas de coleta. O tamanho (volume) dos vasos a ser escolhido depende do tipo de estudo, da espécie-teste e das variáveis que serão estudadas. Por esta razão, objetivou-se com este trabalho avaliar o efeito do tamanho de vasos na habilidade competitiva da soja com as plantas daninhas Urochloa brizantha e Bidens pilosa. O experimento foi conduzido em casa de vegetação e o delineamento foi em blocos ao acaso, em esquema fatorial $3 \times 5$, com quatro repetições. Os fatores considerados no experimento foram três sistemas de competição (soja cultivada isoladamente, soja $+U$. brizantha e soja $+B$. pilosa) e cinco volumes dos recipientes $\left(2,4,7,10\right.$ e $\left.16 \mathrm{dm}^{3}\right)$. O crescimento das plantas de soja foi afetado tanto pelo volume dos vasos quanto pela competição com $U$. brizantha e $B$. pilosa, sendo que $U$. brizantha foi mais competitiva com a soja. Vasos com maiores volumes aumentam os efeitos da competição sobre o crescimento da soja.

Palavras-chave: Bidens pilosa, Glycine max, Urochloa brizantha, volume de vasos.

\section{ABSTRACT}

\section{Interaction between pot size and competition with weeds on soybean growth}

The evaluation of competition effects between soybean and weed is carried out in protected environments. These assays are usually conducted in pots to study the desired effects at different sampling/harvest times. The size of the pots varies with the type of study, plant species and the variables that will be studied. Thus, the aim of this work was to evaluate the effect of the pots size on the competitive ability of soybean with the species Urochloa brizantha and Bidens pilosa. The experiment was conducted in a protected environment and was arranged in a $3 \times$ 5 factorial randomized block design with four replications. The factors considered in the experiment were three systems of competition (soybeans grown alone, soybeans $+U$. brizantha and soybean + B. pilosa) and five pot sizes $\left(2,4,7,10\right.$ and $\left.16 \mathrm{dm}^{3}\right)$. The soybean growth was affected by the pot sizes and the competition with $U$. brizantha and B. pilosa. U. brizantha was more competitive with soybean than B. pilosa. Pots with larger volumetric capacity increased the effects of the competition on the soybean growth.

Key words: Bidens pilosa, Glycine max, Urochloa brizantha, container volume.

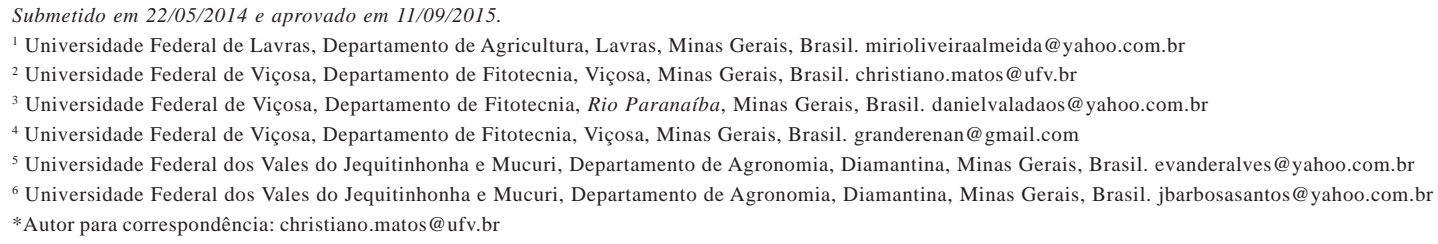




\section{INTRODUÇÃO}

A resposta da soja à interferência das plantas daninhas é dependente de uma série de fatores ligados à comunidade infestante, à própria cultura e, também, aos recursos ambientais relacionados com crescimento e desenvolvimento das espécies. De maneira geral, sob competição, as plantas de soja tendem a incrementar sua altura, como forma de maximizar a captação da radiação e sombrear as plantas daninhas; o acúmulo de massa seca é reduzido, bem como a área foliar e a relação folhas/ramos (Silva et al., 2009). Plantas de soja sob competição tendem a apresentar alterações morfofisiológicas, com reflexo na produtividade (Vollmann et al., 2010).

Estudos sobre competição relativa de espécies daninhas com cultivares de soja mostraram que espécies como Urochloa brizantha cv. BRS Piatã e U. ruziziensis, quando semeadas na densidade de $10 \mathrm{~kg} \mathrm{ha}^{-1}$, aos 24 dias após a emergência da soja, reduziram a produtividade desta cultura de forma distinta, com decréscimos de 3,03 e $16,23 \%$, respectivamente (Saraiva et al., 2013). Diversos autores relatam $U$. brizantha e $B$. pilosa como plantas daninhas de grande importância para diversas culturas (Biffe et al., 2010; Pinotti et al., 2010; Camargo et al., 2011; Pereira et al., 2012), inclusive para soja (Oliveira et al., 2013).

A avaliação dos efeitos da competição das plantas daninhas sobre o crescimento da soja é efetuada por meio de ensaios em ambientes protegidos, para maior precisão experimental e segurança quanto aos resultados obtidos. Esses ensaios geralmente são feitos em recipientes (vasos) em que se testam os efeitos desejados em diferentes épocas de coleta. O tamanho (volume) dos vasos a ser escolhido depende do objetivo do estudo, da espécie a ser estudada e das variáveis que serão analisadas. Experimentos em vasos podem subestimar os efeitos da competição, pois o volume de solo limitado pode restringir o crescimento da planta (parte aérea e raiz) (Kiær et al., 2013). No entanto, essa limitação está diretamente relacionada com as espécies em desenvolvimento e com o tempo de avaliação. Portanto, estudos que abordem a interferência do tamanho dos recipientes em trabalhos com competição de plantas são fundamentais para aprimorar essa técnica.

Considerando-se a importância desses aspectos, objetivou-se com este trabalho verificar o efeito do volume de vasos sobre o crescimento da soja, em convivência com as plantas daninhas $U$. brizantha e B. pilosa.

\section{MATERIAL E MÉTODOS}

O experimento foi conduzido em ambiente protegido. As temperaturas mínima e máxima durante o experi- mento foram de $22^{\circ} \mathrm{C}$ e $28^{\circ} \mathrm{C}$, respectivamente. $\mathrm{O}$ solo utilizado foi do tipo Latossolo Vermelho-Amarelo, textura média, que foi peneirado (malha de $5 \mathrm{~mm}$ ) após secagem ao ar.

O experimento foi realizado no delineamento de blocos ao acaso, com quatro repetições em esquema fatorial $3 \times 5$.

O primeiro fator foi constituído por três sistemas de competição (soja cultivada isoladamente, soja $+U$. brizantha e soja + B. pilosa) e o segundo fator foi representado pelos volumes dos recipientes, vasos preenchidos com 2, 4, 7, 10 e $16 \mathrm{dm}^{3}$ de solo. Foram utilizados vasos plásticos de cor preta, com fundo perfurado e formato cônico, cujas dimensões encontram-se na Tabela 1 .

As análises químicas do substrato utilizado apresentaram os seguintes resultados: $\mathrm{pH}$ (água) $=5,0$; teor de matéria orgânica $=4,7 \mathrm{dag} \mathrm{kg}^{-1}, \mathrm{P}=1,3 \mathrm{mg} \mathrm{dm}^{-3}, \mathrm{~K}=47$ $\mathrm{mg} \mathrm{dm}{ }^{-3}, \mathrm{Ca}=2,4 \mathrm{cmol}_{\mathrm{c}} \mathrm{dm}^{-3}, \mathrm{Mg}=1,2 \mathrm{cmol}_{\mathrm{c}} \mathrm{dm}^{-3}, \mathrm{Al}=$ $0,1 \mathrm{cmol}_{\mathrm{c}} \mathrm{dm}^{-3}, \mathrm{H}+\mathrm{Al}=7,1 \mathrm{cmol}_{\mathrm{c}} \mathrm{dm}^{-3} \mathrm{e} \mathrm{CTC}_{\text {efetiva }}=3,8$ $\mathrm{cmol}_{\mathrm{c}} \mathrm{dm}^{-3}$. Para a adequação do substrato quanto à nutrição, foram aplicados $3,0 \mathrm{~g} \mathrm{dm}^{-3}$ de calcário dolomítico e 3,0 $\mathrm{g} \mathrm{dm}^{-3}$ da formulação 4-14-8 $\left(\mathrm{N}_{-} \mathrm{P}_{2} \mathrm{O}_{5}-\mathrm{K}_{2} \mathrm{O}\right)$. As irrigações foram realizadas diariamente, mantendo-se a capacidade de campo $\pm 80 \%$. A adubação de cobertura foi feita com 300 gramas de cloreto de potássio e 25 gramas de sulfato de amônio, diluídos em 11 litros de água e aplicadas em cada vaso segundo o seu volume: 20 $\mathrm{ml}$ para os vasos de 2 litros; 44,7 $\mathrm{ml}$ para de 4 litros; 80 $\mathrm{ml}$ para de 7 litros; $115 \mathrm{ml}$ para de 10 litros; $193 \mathrm{ml}$ para de 16 litros.

Semearam-se em cada vaso três sementes de soja do cultivar M-SOY $8000 \mathrm{RR}$, conforme tratamento, bem como, dez sementes de Bidens pilosa e de Urochloa brizantha. Após o desbaste, realizado aos cinco dias após emergência, cada vaso ficou com uma planta de cada espécie.

Aos 45 após a emergência, realizou-se a colheita das plantas de soja, sendo separadas em folhas, raízes e colmo. Nessa ocasião, mediu-se o comprimento (ALT - cm) com régua graduada e a área foliar $\left(\mathrm{AF}-\mathrm{cm}^{2}\right)$ das plantas da soja, que foi obtida pela medição de imagens capturadas em câmara fotográfica digital por meio do software ImageTool $^{\circledR}$. O material vegetal foi acondicionado em sacos de papel e levados ao laboratório, onde foram secados durante sete dias em estufa, com circulação forçada de ar, a $52^{\circ} \mathrm{C}$, até atingir massa constante. Posteriormente, foram obtidas a massa da matéria seca das folhas (MSF - g), a massa da matéria seca do caule (MSC g) e a massa da matéria seca das raízes (MSR - g).

Os dados foram submetidos ao teste de homocedasticidade e, em seguida, à análise de variância. Posteriormente, análises de regressões não lineares foram 
realizadas para se avaliarem os efeitos do tamanho de vaso sobre o crescimento da soja em competição com a $U$. brizantha e de $B$. pilosa. O modelo utilizado para descrever o efeito do tamanho dos vasos no crescimento das plantas de soja cultivada isolada ou em competição foi o sigmoidal com três parâmetros, descrito na seguinte equação 1 .

Equação 1:

$\hat{y}=\frac{a}{1+e^{-\left(\frac{X-X o}{b}\right)},}$

em que: $w$ é a variável resposta de interesse, $X$ é o número de dias após emergência e $a, b$, e $X_{0}$ são parâmetros estimados da equação, de tal forma que $a$ é assíntota correspondente ao valor máximo da variável em questão; $b$ é a inclinação da reposta da variável e $X_{0}$ é o ponto de inflexão da curva e corresponde ao volume de vaso necessário para a ocorrência de $50 \%$ de resposta.

\section{RESULTADOS E DISCUSSÃO}

Observou-se interação significativa para os fatores sistemas de competição e volumes de recipientes, para todas as variáveis estudadas. Optou-se por analisar o efeito do sistema de competição dentro do volume do vaso pelo método de regressão, para o que foi utilizado o modelo sigmoidal com três parâmetros (Equação 1).

A soja cultivada isoladamente teve maior acúmulo de massa da matéria seca das folhas (MSF), em comparação com a dos demais tratamentos, em que plantas de soja foram cultivadas com Bidens pilosa e Urochloa brizantha para todos os tamanhos de vasos avaliados, sendo $U$. brizantha o tratamento que mais afetou o acúmulo de MSF da soja com o incremento do volume dos vasos (Figura 1 A). A soja é menos eficiente na extração de água do solo do que algumas plantas daninhas (Ferreira et al., 2011), porém apresenta maior eficiência no uso da radiação, ou seja, maior quantidade de biomassa acumulada por unidade de radiação captada, que Euphorbia heterophylla, B. pilosa e Desmodium tortuosum (Santos et al., 2003). Esses autores afirmam que, apesar de as plantas daninhas avaliadas apresentarem menor eficiência no uso da radiação fotossinte- ticamente ativa, elas mostram grande capacidade competitiva em campo, em razão de a população ser maior e da melhor utilização de outros recursos, como água e nutrientes.

A soja juntamente com $B$. pilosa apresentou menor valor de " $b$ " para MSF, indicando maior tendência de estabilização da curva para esta variável. Plantas de soja em competição com $B$. pilosa necessitaram de menores tamanhos de vasos para atingir a máxima MSF, representada por " $a$ ", em comparação com os dos demais tratamentos (Figura 1A). O decréscimo dos valores do coeficiente " $a$ " da soja cultivada em competição com plantas daninhas, em comparação com o da cultivada isoladamente está relacionada com o efeito das plantas competidoras na MSF da soja.

A soja isolada apresentou maior acúmulo de massa da matéria seca de caule (MSC) com o incremento do tamanho dos vasos, em comparação com o dos tratamentos em competição com as plantas daninhas. Novamente, $U$. brizantha em convivência com a soja foi o tratamento que mais influenciou negativamente o acúmulo de MSC da cultura (Figura 1B). A soja isolada mostrou maior tendência de estabilização da curva com o aumento do tamanho de vasos, isto é, menor valor de " $b$ ". Dessa forma, a MSC da soja atingiria a estabilização quando o MSC for máximo, ou seja, em " $a$ ". No caso da soja isolada, esse valor corresponde a 20,27 g, valor este em que o incremento do tamanho de vasos não afetaria mais o acúmulo de MSC (Figura 1B).

Com relação à massa da matéria seca das raízes (MSR), constatou-se menor incremento no acúmulo de MSR da soja quando esta competia com a $U$. brizantha e B. pilosa (Figura 1C). A soja isolada apresentou maior MSR máximo (" $a$ "), em comparação com os demais tratamentos onde a cultura encontrava-se em competição com o das plantas daninhas, com o aumento do tamanho dos vasos. As parcelas nas quais a soja encontrava-se em competição com as plantas daninhas apresentaram menores valores de inclinação da curva (“ $b$ ”), em comparação com a da testemunha. Assim, em estado de competição pode-se afirmar que a MSR da soja tem maior tendência de estabilização da curva com o aumento do tamanho dos vasos, sendo importante destacar que, com

Tabela 1: Dimensões dos vasos correspondentes ao volume de solo utilizado no experimento

\begin{tabular}{lccc}
\hline Volume de solo $\left(\mathbf{d m}^{3}\right)$ & \multicolumn{3}{c}{ Medida dos vasos $(\mathbf{d m})$} \\
\cline { 2 - 4 } & Altura & Diâmetro superior & Diâmetro inferior \\
\hline 2 & 1,40 & 1,70 & 1,30 \\
4 & 2,00 & 2,00 & 1,60 \\
7 & 2,10 & 2,50 & 1,80 \\
10 & 3,00 & 2,50 & 2,25 \\
16 & 3,00 & 3,00 & 2,55 \\
\hline
\end{tabular}

Rev. Ceres, Viçosa, v. 62, n.6, p. 524-530, nov-dez, 2015 
relação ao crescimento do sistema radicular, a soja em estado de competição necessita de vasos menores, por causa da redução do crescimento das raízes, provocada pela presença das plantas daninhas.
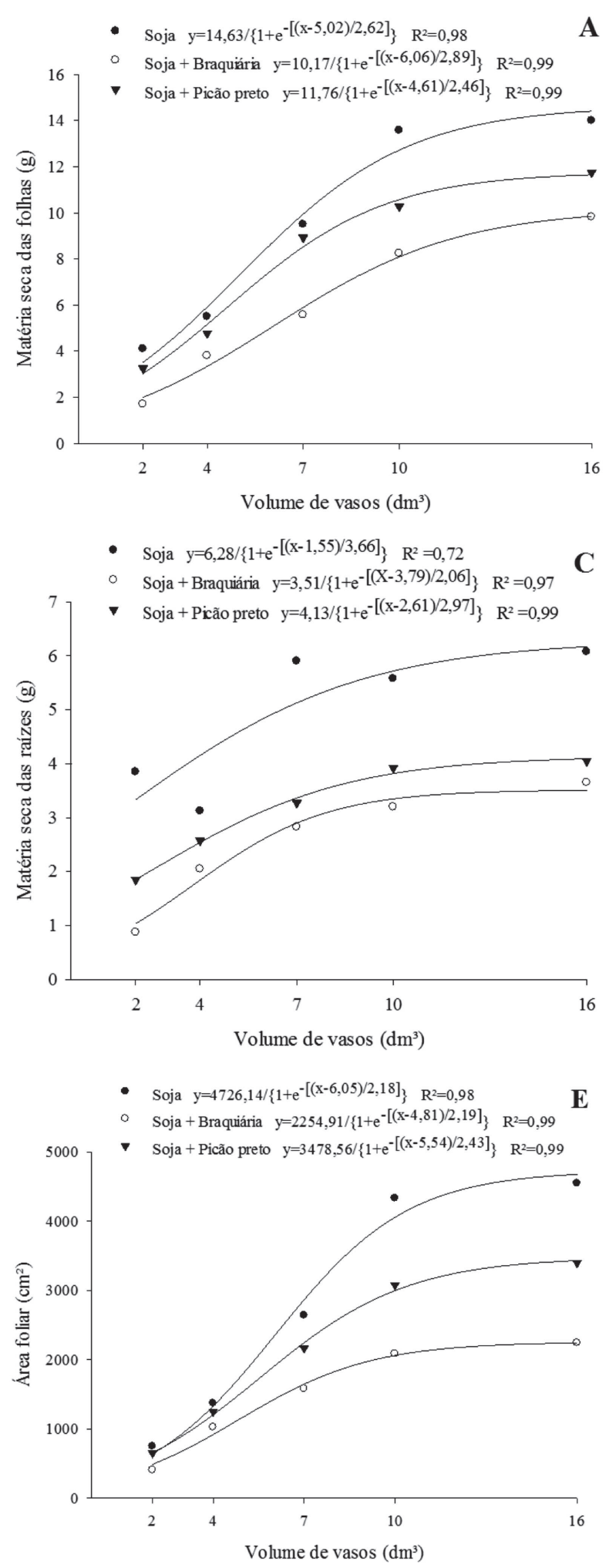

$\mathbf{E}$
Para a massa da matéria seca total (MST), mais uma vez a soja, crescendo sem competição, apresentou maior tendência de crescimento em comparação com o dos demais tratamentos, com o incremento do volume dos
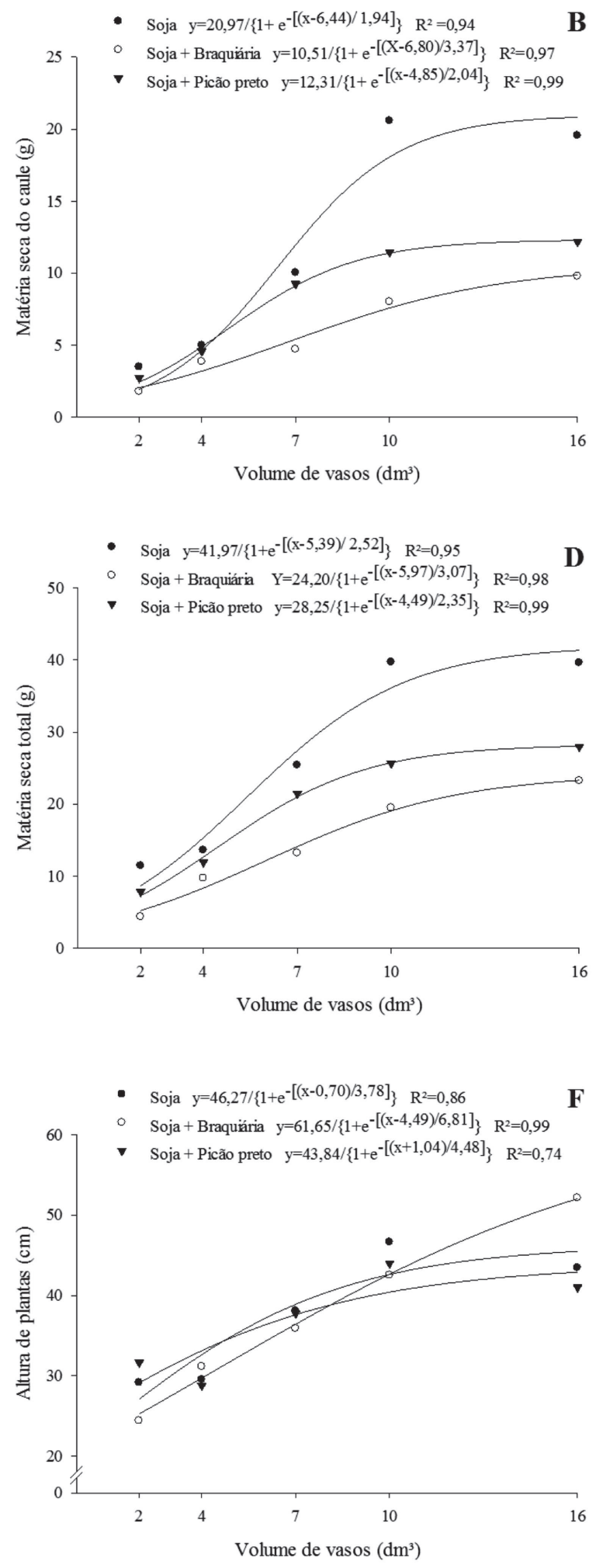

Figura 1: A) Massa da matéria seca de folhas (MSF), B) Massa da matéria seca de caule (MSC), C) Massa da matéria seca das raízes (MSR), D) Massa da matéria seca total (MST), E) Área foliar (AF) e F) Altura de plantas (ALT) de soja sem competição; soja competindo com braquiária e soja competindo com picão preto, cultivadas em diferentes volumes (tamanhos) de vasos. 
vasos (Figura 1D). Deve-se considerar que a população com que as plantas daninhas ocorrem nas lavouras não apresenta a sua real habilidade de competição, quando, na realidade, o efeito decorre do maior número de indivíduos em uma população e não da capacidade particular de cada indivíduo em competir com as culturas (Bianchi et al., 2006). Entretanto, B. pilosa, além de estar em alta densidade e comumente presente em áreas com cultivo de soja, é uma espécie que apresenta elevado potencial competitivo; individualmente, a espécie é capaz de submeter a cultura a significativas reduções do acúmulo de matéria seca.

A soja cultivada isoladamente também apresentou maior MST máximo " $a$ " (Figura 1D). A soja em competição com $U$. brizantha apresentou maior " $b$ ", ou seja, a curva relacionada com este tratamento apresenta menor tendência de estabilização, exigindo, assim, vasos maiores para que a curva atinja o MST máximo (“ $a$ ”).

$\mathrm{O}$ tratamento em que a soja foi cultivada isoladamente apresentou maior incremento da área foliar (AF) com o aumento do volume dos recipientes, em comparação com o dos tratamentos em que a cultura encontrava-se em estado de competição (Figura 1E). A maior AF máxima foi observada para soja cultivada isoladamente e o menor valor desta variável foi constatado para o tratamento em que a soja competia com plantas de $U$. brizantha. A soja isolada apresentou menor valor de " $b$ ", consequentemente com maior tendência de estabilização da curva e exigência de menores tamanhos de vasos para a estabilização no ponto de AF máximo.

Como as plantas $\mathrm{C}_{4}$ apresentam alta necessidade de luz para manutenção de níveis adequados do metabolismo, as plantas que crescem primeiro e sombreiam as demais apresentam taxa de fotossíntese líquida e acúmulo de massa superiores, dominando a área e inibindo, assim, o crescimento das plantas menos competitivas (Zanine \& Santos, 2004); assim U. brizantha tem um crescimento inicial mais rápido e sombreia as plantas de soja, reduzindo o seu crescimento.

Todos os tratamentos mostram tendência de incremento da estatura das plantas (ALT) com o aumento do volume de vasos; no entanto, maior incremento do ALT da soja foi observado para o tratamento da soja em estado de competição com a $U$. brizantha (Figura 1F). Esse resultado pode ser atribuído a alterações da qualidade e da intensidade da luz incidente sobre as plantas de soja, que irão afetar o desenvolvimento das plantas cultivadas (Vollmann et al., 2010). A competição com plantas daninhas estimula alterações do crescimento em altura e na relação parte aérea/raiz da soja, de forma que, morfologicamente, plantas de soja tendem a ser mais altas quanto maior for a competição com as plantas daninhas (Vollmann et al., 2010). Plantas da comunidade infestante refletem luz em determinado comprimento de onda, o que normalmente torna possível o reconhecimento de plantas vizinhas pelas culturas; assim, antes de a competição direta por água, luz e nutrientes se estabelecer, a cultura investe em estratégias para evitar o sombreamento pelas plantas daninhas (Liu et al., 2009). Esse efeito depende da qualidade da luz recebida, da cultura e da composição da comunidade infestante.

A variação da qualidade da luz é percebida por pigmentos (fitocromos, criptocromo e fitotropina), mesmo antes de ocorrer o sombreamento, e objetiva ajustar o crescimento da planta em função da presença de vizinhos (Taiz \& Zeiger, 2009). A relação da radiação vermelho/vermelho distante, percebida principalmente pelos fitocromos, tem papel importante na indução de alterações moleculares, morfológicas e fisiológica das plantas (Liu et al., 2009). O sombreamento das plantas, detectado pela elevada incidência da luz vermelho distante, faz com que elas aloquem maior disponibilidade de recursos para investimento no crescimento da parte aérea, normalmente afetando o desenvolvimento do sistema de raízes e, com isso, podendo comprometer a disputa por recursos do solo (Rajcan et al., 2004; Liu et al., 2009).

A maior ALT máxima foi observada para o tratamento em que a soja foi cultivada juntamente com plantas de $U$. brizantha, além de maior " $b$ ", ou seja, menor tendência de estabilização da curva (Figura 1F).

Plantas de soja cultivadas isoladamente apresentaram tendência para reduzir a percentagem de alocação de matéria seca nas raízes e aumentá-la no caule, à medida que se aumentou o volume dos vasos (Figura 2A). Já em plantas de soja cultivadas em competição com B. pilosa e $U$. brizantha, a redução da alocação de massa seca na raiz, com aumento do volume dos vasos, foi menos pronunciada que para a testemunha (Figuras 2B e C). Essa diferença no padrão de distribuição de massa seca de plantas de soja indica que, nos menores volumes de vasos, há uma tendência de a competição reduzir mais o crescimento da raiz. Além disso, os sistemas radiculares da soja e das plantas daninhas crescem rapidamente, ocupando em poucos dias todo o volume do substrato, de forma que um recipiente pequeno limita o crescimento das plantas.

Boa parte da competição entre plantas ocorre abaixo do solo. Na competição abaixo do solo, diferentemente da competição acima do solo, que, primariamente, envolve uma simples fonte (luz), as plantas competem por vários recursos, incluindo água e pelo menos 20 minerais essenciais, que diferem em peso molecular, valência, estado de oxidação e mobilidade dentro do solo. A competição abaixo do solo frequentemente reduz o desempenho das plantas de forma mais efetiva que a competi- 
A

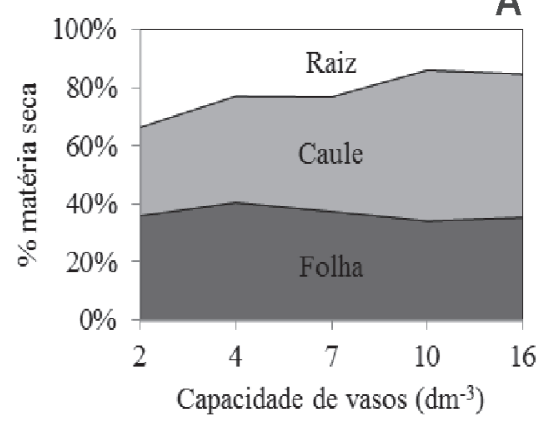

B

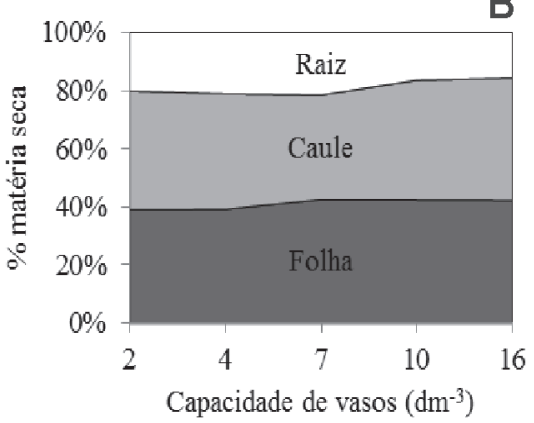

C

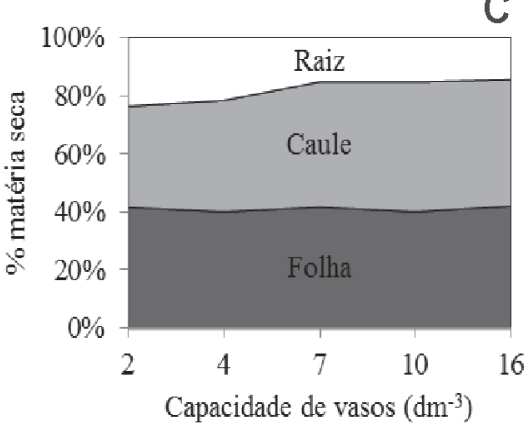

Figura 2: Partição de matéria seca (\%) de plantas de soja, cultivada isoladamente (A), em competição com Urochloa brizantha (B) e em competição com Bidens pilosa (C), em diferentes volumes (tamanhos) de vaso.

ção acima do solo, principalmente para as plantas concorrentes de menor porte, em solo de baixa fertilidade, quando o competidor é uma gramínea, comparado a plantas de folha larga ou leguminosas e quando o competidor é uma espécie não cultivada (Kiær et al., 2013).

$\mathrm{O}$ aumento da densidade de plantas daninhas em competição com a soja provoca maiores reduções do crescimento e diminui a absorção de nutrientes pela cultura (Carvalho et al., 2010); além disso, quanto maiores a infestação e o período de convivência de plantas daninhas com a soja, maiores são suas perdas de rendimento de grãos (Ferreira et al., 2009). Assim, para plantas cultivadas em estado de competição correspondente a uma alta densidade de plantas, em vasos de pequeno volume de substrato, aumentando-se o tamanho dos vasos, a densidade de plantas decresce, considerando-se também que o volume diminuto aumenta a competição, principalmente por espaço, além da alta competição por água e nutrientes.

De maneira geral, observa-se, nas Figuras 1 e 2, que, para a maioria das variáveis estudadas, e independentemente do tratamento, houve um aumento do crescimento da soja com o aumento do tamanho de vasos; portanto, a disponibilidade de substrato (solo) limitou o crescimento da soja. Porém, de maneira geral, a resposta da soja à competição com plantas daninhas pode ser observada para todos os volumes de vasos, de tal forma que a convivência com B. pilosa e $U$. brizantha reduziu o crescimento da soja, sendo que a braquiária proporcionou as maiores reduções de crescimento. No entanto, maiores volumes de vasos proporcionaram maiores contrastes na resposta da soja à competição com estas plantas daninhas.

\section{CONCLUSÕES}

O crescimento da soja é severamente reduzido em competição com as plantas daninhas e a Urochloa brizantha foi a planta com maior potencial de redução do crescimento da soja.
O volume do recipiente (vaso) altera a magnitude das respostas da cultura à competição com as plantas daninhas, sendo que vasos maiores aumentam os efeitos da competição. Portanto, vasos maiores são mais adequados para estudar os efeitos da competição entre plantas.

\section{AGRADECIMENTOS}

Os autores agradecem ao Conselho Nacional de Desenvolvimento Científico e Tecnológico (CNPq), à Fundação de Amparo à Pesquisa do Estado de Minas Gerais (FAPEMIG) e à Coordenação de Aperfeiçoamento de Pessoal de Nível Superior (CAPES), pelo apoio financeiro na execução deste trabalho.

\section{REFERÊNCIAS}

Bianchi MA, Fleck NG \& Lamego FP (2006) Proporção entre plantas de soja e plantas competidoras e as relações de interferência mútua. Ciência Rural, 36:1380-1387.

Biffe DF, Constantin J, Oliveira Jr RS, Franchini LHM, Rios FA, Blainski E, Arantes JGZ, Alonso DG \& Cavalieri SD (2010) Período de interferência de plantas daninhas em mandioca (Manihot esculenta) no noroeste do Paraná. Planta Daninha, 28:471-478.

Camargo D, Bispo KL \& Sene L (2011) Associação de Rhizobium sp. a duas leguminosas na tolerância à atrazina. Revista Ceres, 58:425431.

Carvalho LB, Bianco S \& Guzzo CD (2010) Interferência de Euphorbia heterophylla no crescimento e acúmulo de macronutrientes da soja. Planta Daninha, 28:33-39.

Ferreira EA, Silva AF, França AC, Galon L, Concenço G, Ferreira FA, Aspiazú I \& Silva AA (2009) Efeitos de períodos de competição nas características morfológicas de grãos de soja. Revista Trópica, 3:5360.

Ferreira EA, Aspiazú I, Galon L, Concenço G, Silva AF \& Reis LAC (2011) Características fisiológicas da soja em relação a espécies de plantas daninhas. Revista Trópica, 5:39-47.

Kiær LP, Weisbach AN \& Weiner J (2013) Root and shoot competition: a meta-analysis. Journal of Ecology, 101:1298-1312.

Liu JG, Mahoney KJ, Sikkema PH \& Swanton CJ (2009) The importance of light quality in crop-weed competition. Weed Research, 49:217224.

Oliveira P, Nascente AS \& Kluthcouski J (2013) Soybean growth and yield under cover crops. Revista Ceres, 60:249-256. 
Pereira GAM, Lemos VT, Santos JB, Ferreira EA, Silva DV, Oliveira MC \& Menezes CWG (2012) Crescimento da mandioca e plantas daninhas em resposta à adubação fosfatada. Revista Ceres, 59:716-722.

Pinotti EB, Bicudo SJ, Curcelli F \& Dourado WS (2010) Levantamento florístico de plantas daninhas na cultura da mandioca no município de Pompéia - SP. Revista Raízes e Amidos Tropicais, 6:120-125.

Rajcan I, Chandler K \& Swanton CJ (2004) Red-far-red ratio of reflected light: a hypothesis of why early-season weed control is important in corn. Weed Science, 52:774-778.

Santos JB, Procópio SO, Silva AA \& Costa L C (2003) Captação e aproveitamento da radiação solar pelas culturas da soja e do feijão e por plantas daninhas. Bragantia, 62:147-153.

Saraiva AS, Erasmo EAL, Mata JF, Dornelas BF, Dornelas DF \& Silva JIC (2013) Density and sowing season of two Brachiaria species on the soybean culture. Planta Daninha, 31:569-576.
Silva AF, Concenço G, Aspiazú I, Ferreira EA, Galon L, Coelho ATCP, Silva AA \& Ferreira FA (2009) Interferência de plantas daninhas em diferentes densidades no crescimento da soja. Planta Daninha, 27:7584.

Taiz L \& Zeiger E (2009) Fisiologia vegetal. $4^{\mathrm{a}}$ ed. Porto Alegre, Artmed. 819 p.

Vollmann J, Wagentristl H \& Hartl W (2010) The effects of simulated weed pressure on early maturity soybeans. European Journal of Agronomy, 32:243-248.

Zanine AM \& Santos EM (2004) Competição entre espécies de plantas - uma revisão. Revista da FZVA, 11:10-30. 